\title{
GENEALOGI RADIKALISME ISLAM \\ KLASIK DAN KONTEMPORER
}

\author{
Mufaizin \\ STAI Darul Hikmah Bangkalan \\ faizin@darul-hikmah.com
}

\begin{abstract}
ABSTRAK
Istilah radikalisme menjadi perbincangan hangat yang kerap dibahas di berbagai kesempatan, Radikalisme menjadi masalah penting dan utama bagi umat islam dan bangsa Indonesia saat ini, isu tersebut telah mencoreng nama islam, Islam di labeli sebagai agama teror dan menyukai jalan kekerasan dalam mendakwahkan agamanya, sehingga muncullah "Islamofobia"di berbagai Negara terutama di negara yang notabene penduduk muslimnya minoritas, radikalisme dalam arti gerakan yang menggunakan kekerasan dalam mengajarkan keyakinan, dianggap berseberangan dengan islam sebagai agama kedamaian yang mengajarkan sikap berdamai. islam tidak pernah membenarkan praktek pengggunaan kekerasan dalam menyebarkan agama, faham keagamaan serta faham politik, akan tetapi memang tidak dapat dibantah dalam fenomena historis terdapat kelompok islam tertentu yang menggunakan jalan kekerasan untuk mencapai tujuan idiologis maupun politis, yang dalam bahasa peradaban saat ini disebut dengan radikalisme.
\end{abstract}

\section{Keyword: Islam, Genealogi, Radikalisme}

\section{A. PENDAHULUAN}

Sejarah telah merekam bagaimana Trackrecord Islam dalam mewujudkan perdamaian. pada masa awal berkembangnya Islam telah berhasil meredam ketegangan dan konflik antar suku dan golongan di jazirah Arab bahkan pernah mendamaikan antar agama. dengan membangun kerukunan hidup dalam sebuah Negara yang bernama Madinah. masa tersebut adalah masa paling ideal (KhairulQurn) dalam sejarah umat Islam karena saat itu nabi Muhammad SAW merupakan representasi dari Islam itu sendiri, masih mendampingi umatnya sehingga Islam bisa berlaku secara efektif dan dalam real yang sebenarnya.

Radikalisme sebagai suatu gerakan bukanlah fenomena baru dalam dunia Islam. Dalam lembaran sejarah Islam di masa lalu, setelah wafatnya Rasulullah SAW terutama pasca wafatnya sahabat Usman. Sebutlah sebuah aliran keagamaan dalam Islam, yaitu Khawarij adalah contoh aliran kalam yang paling terkenal dengan fahamnya yang radikal dan tidak kenal kompromi. Hal ini dibuktikan dengan 
tindakan kekerasan dalam mencapai tujuannya, diantaranya melakukan pembunuhan terhadap sahabat Nabi pasca Perjanjian damai atau Tahkim (Arbitrase) yang dianggap telah menyeleweng dari ajaran Tuhan. Khawarij mungkin sudah tiada, Namun ia meninggalkan pola dasar bagi gerakan-gerakan ekstrem di masa selanjutnya, pola gerakan khawarij yang radikal ini kemudian ditiru oleh kelompok islam yang hidup di era modern seperti gerakan pemurnian ajaran agama yang di pelopori oleh Wahhabisme-Salafisme, Hizbut-tahrir, Al-Qaeda dan ISIS, serta gerakan lain yang memiliki kesamaan pola pikir dengan kelompok khawarij dimasa lalu. Karena itulah, penulis berupaya membuka kembali lembaran sejarah radikalisme dalam Islam agar persepsi masyarakat dan dunia tentang Islam dan Radikalisme tercerahkan, sehingga dengan ini bisa diketahui bahwa radikalisme bertentangan dengan Islam, kelompok dan segelintir umat' islamlah yang menjadikan wajah Islam yang damai dan ramah menjadi radikal dan mengerikan.

Kajian dalam tulisan ini menggunakan metode library research yaitu penelusuran terhadap data dari buku dan referensi yang relevan dan berkaitan denganenggunakan pendekatan historis, selanjutnya data-data tersebut di olah dan di analisa, sehingga ditemukan kesimpulan sesuai dengan tema yang dibahas.

\section{B. PEMBAHASAN}

\section{Pengertian Radikalisme}

Radikalisme secara bahasa berasal dari kata "Radict" yang memiliki arti akar atau dasar, mendasar dan prinsip. Radikal adalah sebuah perilaku yang menjurus pada tindak kekerasan, Radikalis adalah orang yang melakukan tindak kekerasan. Sedangkan Radikalisme faham/sifatnya yang terlahir dari radikal.

Dalam kamus Bahasa Indonesia, radikal bermakna menyeluruh, habishabisan, amat keras dalam menuntut perubahan undang-undang pemerintahan dan sebagainya. Sedangkan radikalisme diartikan sebagai paham yang menganut pola radikal dalam menuntut perubahan politik dst. ${ }^{1}$

Dalam bahasa Arab tidak ditemukan padanan kata radikalisme secara persis. Radikalisme tidak pernah diserap menjadi sebuah kata ataupun diterjemahkan secara pasti. Karena istilah radikal adalah murni produk barat yang sering dihubungkan dengan fundamentalisme dalam islam. Fundamentalisme dalam islam serig dihubungkan dengan istilah lain, seperti "Ekstrimisme islam", "Islam radikal", "Revivalisme" Atau "Islamisme". ${ }^{2}$

Secara Terminologis, Radikalisme agama berarti perilaku keagamaan yang mengambil karakter keras sekali antara dua pihak yang bertikai bertujuan

\footnotetext{
${ }^{1}$ Dendy sugono,Kamus Bahasa Idonesia,(Jakarta; Pusat Bahasa, 2008), 1246

2 Anzar Abdullah, Gerakan Radikalisme Dalam Islam Perspektif Historis, (Makassar; ADDIN, Vol.10, no 1,2016)
} 
merealisasikan target target tertentu atau mengubah situasi sosial tertentu dengan cara yang menyalahi aturan agama. ${ }^{3}$

Menurut Azyumardi Azra, radikalisme adalah gagasan dan tindakan yang bertujuan untuk melemahkan dan merubah tatanan politik mapan biasanya dilakukan dengan cara kekerasan, dirubah dengan sistem baru yang diyakini sebagai system yang lebih baik. ${ }^{4}$

Menurut Badan Nasional Penanggulangan Terorisme (BNPT), Radikalisme merupakan suatu sikap yang mendambakan perubahan secara total dan bersifat revolusioner dengan menjungkirbalikkan nilai-nilai yang ada secara drastis lewat kekeraan (Violence) dan aksi-aksi yang ekstrem. Ada beberapa ciri yang bisa dikenali dari sikap dan paham radikal. 1) intoleran (tidak mau menghargai pendapat \&keyakinan orang lain), 2) fanatik (selalu merasa benar sendiri; menganggap orang lain salah), 3) eksklusif (membedakan diri dari umat Islam umumnya) dan 4) revolusioner (cenderung menggunakan cara-cara kekerasan untuk mencapai tujuan). ${ }^{5}$

Berdasarkan beberapa pengertian yang dipaparkan di atas dapat disimpulkan bahwa radikalisme adalah faham, aliran atau gerakan yang mengingikan perubahan atau pembaharuan sosial dan politik dengan cara kekerasan dan drastis, Namun, dalam artian lain, esensi radikalisme adalah inti dari perubahan itu cenderung menggunakan kekerasan

\section{Radikalisme di era klasik}

Radikalisme adalah masalah klasik. hampir seluruh peradaban pernah tertimpa oleh radikalisme, dalam Islam sendiri ia adalah sebuah masalah yang secara genetik sudah muncul bahkan sejak zaman nabi Muhammad SAW masih hidup. dalam sebuah riwayat diceritakan:

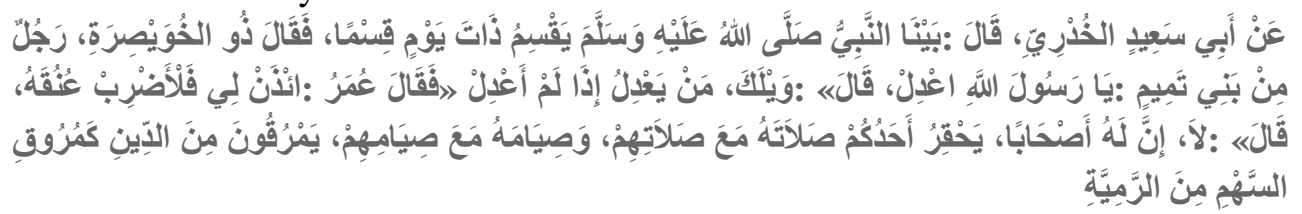

Ketika nabi membagi dan memberikan harta jarahan (Ghanimah) tiba-tiba seorang laki-laki datang memprotes dan mengkomplain beliau seraya berkata: berlaku adillah engkau wahai Muhammad" nabi menjawab "celaka kamu, jika aku tidak adil maka siapa lagi yang akan adil”?. kemudian sahabat Umar berkata: izinkan

\footnotetext{
3 Tim ASWAJA NU CENTER JATIM, Khazanah ASWAJA, (Surabaya; ASWAJA NU CENTER PWNU JATIM, 2016), hlm.374

${ }^{4}$ Azyumardi Azra, Transformasi politik Islam, (Jakarta; Prenada Media, 2016), hlm.155.

5 Badan Nasional Penanggulangan Terorisme (BNPT), "Strategi menghadapi paham radikalisme terorisme_-Isis", Artikel
} 
saya untuk memenggal lehernya wahai Rasul, lalu nabi mencegah sahabat Umar dan bersabda:

"Sesungguhnya dia memiliki pengikut yang salat dan puasa mereka membuat kalian merasa minder akan salat dan puasa kalian akan tetapi mereka keluar dari agama seperti keluarnya anak panah dari busurnya", 6

Dalam riwayat lain disebutkan yang artinya sebagai berikut:

Nanti akan muncul diantara umatku kaum yang membaca al-Qur'an, bacaan kamu tidak apa-apanya dibandingkan bacaan meraka, dan shalat kamu juga tdak ada apa-apanya dibandingkan shalat mereka, serta puasa kamu juga tidak ada apaapanya dibandingkan puasa mereka, mereka membaca al-Qur'an sehingga kamu akan menyangka bahwa alqur'an itu milik mereka saja, padahal sebenarnya alQur'an itu akan melaknat mereka, tidaklah salat mereka melalui kerongkongan mereka, mereka itu akan memecah agama islam sebagaimana keluarnya anak panah dari busurnya. (HR. Muslim, juga diriwayatkan dengan redaksi yang berbeda oleh Imam Bukhori dan Abi daud).

Inilah Kelompok yang telah nabi Prediksi kemunculannya di tengah-tengah kita, kelompok yang Ghuluw (berlebih-lebihan) dalam beribadah. yang merasa dirinya paling benar, ibadahnya paling rajin, bacaan Qur'annya paling bagus, Sampai-sampai sahabat nabi yang kualitas ibadahnya luar biasa masih dikatakan oleh nabi akan merasa minder jika dibandingkan dengan puasa dan shalat orangorang khawarij.

Secara Etimologis, kata khawarij berasal dari bahasa Arab "kharaja" yang berarti keluar atau memberontak, ${ }^{7}$ muncul, timbul, atau memberontak. Menutut lois ma'liuf, khawaij berarti golongan yang keluar atau memberontak terhadap peerintah dan jamaah.. ${ }^{8}$ Dari pengertian ini, kata tersebut dapat juga dimaknai sebagai golongan orang Islam atau Muslim yang keluar dari kesatuan umat Islam.

Secara terminologis, Khawarij adalah suatu golongan yang memisahkan diri dari kelompok ali bin abi thalib karena tidak menyepakati keputusan ali yang menerima tahkim dari mu'awiyah dalam perang Shiffin. ${ }^{9}$

As-Syahrastani bependapat, bahwa setiap orang yang menyempal dari pemimpin yang sah, yang sudah disepakati umat itu dinamakan khawarij, baik pada masa sahabat d era Khulafa-Rasyidin maupun pada masa sesudah mereka di era

\footnotetext{
${ }^{6}$ Muhammad Isma'il Al-Bukhori, Shohih Bukhori, (Beirut; darul-kutub-ilmiyah, 1998), jil II hlm.503.

${ }^{7}$ Ahmad Warson Munawwir, Kamus Al-MUnawwir, cet.25.(Surabaya; Pustaka progresif, 2002), hlm 329-330

${ }^{8}$ Louis Ma'luf, Al-Munjid Fillughah Wal A'lam, cet. 28.(Beirut; Darul-Masyriq, 2000), Hlm. 183

9 Abu Zahrah, Tarikhul-Madzahib-Islaamiyah, penj; Abdurrahman Dahlan dan ahmad Qorib, cet 1(Jakarta; logos, 1996), hlm 63
} 
Tabi'n dan para pemimpi lain sepanjang masa.dalam fikih orang-orang yang melakukan peberontakan terhadap pemerintah yang sah disebut Bughot. ${ }^{10}$

Ketika konflik antara sahabat Ali dan Muawiyah, saat itu sahabat Ali menerima tawaran damai (Tahkim/Arbitrase) dari kelompok Muawiyah sebagaimana telah diketahui beberapa orang yang mulanya mendukung sahabat Ali berbalik melawannya di samping juga Muawiyah serta menyeru agar berhukum dengan Hukum Allah. La hukma illa lillah kata mereka, sambil mengutip surat alMaidah ayat 44 mereka menyerang kelompok yang tidak sepaham dengan mereka, mereka mengkafirkan siapa saja yang melakukan dosa besar. ini dilakukan agar perlawanan mereka terhadap para sahabat nabi mendapat legitimasi Syariah. sehingga mereka menganggap pembunuhan terhadap sahabat Ali legal menurut syariat karena melakukan dosa besar yaitu menerima keputusan tahkim (Arbitrase) dari pihak Muawiyah dari sinilah kemudian lahir gerakan teologis radikal dalam islam yang dipelopori oleh kelopok "Khawarij”.

Sejarah perilaku kekerasan dalam Islam, umumnya terjadi karena persoalan politik, kemudian berdampak kepada keyakinan beragama (Teologis) sebagai pedoman. Hal ini adalah fakta sejarah yang tidak terbantahkan. meski pembunuhan terhadap pemimpin telah terjadi ketika Umar menjadi khalifah. Namun, gerakan radikalisme yang sistematis dan terorganisir baru dimulai setelah terjadinya Perang Shiffin di masa kekuasaan Ali bin Abi Thalib.. Mereka tak segan-segan mengkafirkan dan melakukan kekejaman terhadap orang islam yang tidak sependapat, Radikalisme gerakan ini bukan saja pada aspek pemahaman, tetapi juga pada aspek tindakan. Setelah perang shiffin mereka melakukan aksi teror kepada kelompok lain yang berbeda dan dianggap salah, puncaknya ialah upaya pembunuhan terhadap sejumlah sahabat yaitu Ali bin Abi Thalib, Muawiyah bin Abi Sufyan, dan Amr bin Ash, meski akhirnya upaya pembunuhan tersebut gagal dan hanya Ali bin abi thalib yang berhasil dibunuh oleh seorang laki-laki bernama Abdurrahman bin Muljam.

Watak keras kaum khawarij dibentuk oleh latar belakang mereka yang pada umumnya berasal dari orang-orang arab Badui, hidup dipadang pasir yang serba tandus membuat mereka memilik sifat sederhana dalam cara hidup dan pemikiran, namun keras hati dan berani. ${ }^{11}$ Menjelaskan karakter orang khawarij, Ahmad amin menuturkan karakter menonjol dari kalangan ini, Pertama, mereka adalah orangorang yang memiliki kesungguhan dan ketekunan dalam ibadah, mereka juga dikenal sebagai ahli puasa dan shalat. Kedua, mereka merupkan kumpuan orang-

\footnotetext{
${ }^{10}$ ASWAJA CENTER NU JATIM, Op Cit. hlm.330

${ }^{11}$ Harun nasution, Teologi Islam, Aliran-Aliran Sejarah Analisa dan Perbandingan, cet.5 (Jakarta; UI-Pres.2018), hlm .13
} 
orang yang sangat teguh menjga kemurnian akidahnya, bahkan rela berperang demi mempertahankannya. Ketiga, mereka juga merupakan orang-orang yang terkenal gigih dan berani, dua sifat itu tidak hanya dimiliki oleh kaum laki-laki bahkan para wanita khawarij pun rela bersimbah darah dimedan perang. ${ }^{12}$

Radikalisme Khawarij sebagai pemberontak telah tercatat dalam lembaran sejarah. Tidak hanya di masa Ali, Khawarij meneruskan perlawanannya terhadap kekuasaan Islam resmi, baik di zaman Dinasti Bani Umayyah maupun Abbasiyah. ${ }^{13}$ Pemegang kekuasaan yang ada pada waktu itu mereka anggap Kafir dan telah menyeleweng dari islam karenanya mereka harus dilawan dan dijatuhkan. Oleh karena itu, mereka memilih Imam dari kalangan mereka dan membentuk pemerintahan sendiri.

\section{Radikalisme di era kontemporer}

Khawarij secara bentuk dan gerakannya sudah lenyap, namun karakter dan pola pikirnya masih terus mengikuti perjalanan sejarah islam. Saat ini karakter khawarij melekat pada kelompok islam yang begitu mudahnya mengkafirkan dan menyesatkan golongan islam lain yang punya perbedaan pendapat dan faham dengan mereka. Karakter khawarij juga sering kita temukan dalam diri orang islam yang kerap menggunakan kekerasan dan melegalkan tindakan Anarkisme dan Terorisme dengan atas nama menegakkan agama allah.

Menurut penulis, di era modern ini banyak kelompok yang menerapkan pola radikal dalam pemikiran dan gerakan, secara garis besar radikalisme di era modern dapat dipetakan menjadi dua katagori, Pertama ,radikalisme dalam beragama yaitu orang-orang atau kelompok yang memaksakan pemahaman keagamaanya, menyesatkan dan mengkafirkan kelompok lain yang memiliki perbedaan keyakinan dan faham, bahkan karena perbedaan pemahaman tersebut mereka tak segan-segan menghalalkan darah walaupun sesama muslim, Kedua, radikalisme dalam idiologi politik. Ialah kelompok yang mengingikan perubahan system politik dan tatanan sosial yang telah mapan dengan gagasan baru yang diyakini oleh mereka sebagai system yang paling benar dan tepat. karena perbedaan pemahaman ini juga mereka tak segan-segan mengkafirkan sesama muslim dan membunuhnya.

Tanpa beramaksud menyudutkan serta menjustifikasi kelompok tertentu, Dari uraian diatas jika ditelisik lebih jauh lagi maka akan banyak kita dapati kelompok-kelompok ekstrem dan radikal dalam islam, semisal gerakan pemurnian ajaran agama (Salafi-Wahhabi), Hizbut-tahrir, Ikhwanul-muslimin (IM) Al-Qaeda dan ISIS, atau di Indonesia seperti Majlis Mujahidin Indonesia (MMI), Laskar Jihad, Jamaah Ansharud-Daulah (JAD), Jamaah Ansharut-Tauhid dan gerakan lain yang memiliki kesamaan pola pikir dengan kelompok khawarij dimasa lalu, yang

\footnotetext{
${ }^{12}$ Ahmad Amin, Fajr-islam, (Beirut; Darul-Kutub-Ilmiyah. 2004), hlm 70

${ }^{13}$ Harun nasution, Op Cit. hlm 14
} 
menginginkan perubahan baik dalam paham keagamaan maupun system politik dan tatanan sosial secara drastis dengan menggunkan teror dan cara-cara radikal.

yang menarik adalah penjelasan yang disampaikan oleh M.Najih arRamadhani bahwa embrio dan akar Idiologi radikal lahir dari paham Salafisme atau Wahhabisme. Pola ajaran purifikasi yang digaungkan kelompok tersebut menghantam telak akal sehat; agama tidak lagi digunakan untuk menjadi pemandu menuju kebenaran, melainkan sebagai alat untuk menyulut permusuhan dan kehancuran. ${ }^{14}$

Dalam perjalanannya kelompok ini bekerja sama dengan penguasa tempat daerah mereka tinggal, di antara aksi radikal yang mereka lakukan adalah pembongkaran terhadap makam-makam sahabat rasulullah SAW. Selanjutnya mereka berkolaborasi dengan keluarga Ibnu $S a$ 'ud yang dikenal memiliki kekuatan militer pada saat itu lalu memproklamirkan jhad terhadap kelompok lain, dengan memanfaatkan idiologi Wahhabi untuk menguasai semenanjung arab. puncaknya kelompok tersebut banyak melakukan pembunuhan terhadap sesama muslim bahkan para ulama' sebagaimana catatan Syekh Idahram dalam bukunya "Sejarah berdarah sekte Salafi-Wahhabi".

Disisi lain pada masa Kontemporer, radikalisme muncul sebagai reaksi atas penjajahan barat. Negara-negara barat banyak menjajah Negara-negara islam di timur tengah, sebelumya ketika penjajahan barat baru muncul, umat islam mencaricari penyebab kenapa islam semakin mundur dan kalah dalam beberapa bidang. Padahal, sebagaimana sering dijelaskan bahwa agama islam adalah agama yanag luhur dan tidak tekalahakan (Al-islamu-Ya'lu-Wala-Yu'la alaih), menaggapi realitas ini muncullah Shafwah-diniyah (kesadaran keagamaan) dalam benak beberapa kaum muslimin. Terutama ketika memasuki abad 19 masehi.

Fenomena Shafwah-diniyah merupakan hal yang positif.namun karena memunculkan kelompok-kelompok yang menjadikan Takfir sebagai hobi, Ekstrimis sebagai metode, dan Terorisme sebagai solusi, maka fenomena ini menjadi negatif. bahkan kesadaran keagamaan ini menjadi tema sentral bagi semua kelompok jihad dan pembaruan. Kelompok ini semakin menemukan momennya ketika penjajahan barat kian hari kian menjadi, terlebih saat Inggris memasuki wilayah paling sensitif di dunua islam: Yarussalem. dengan mendirikan Negara Israel di tanah Palestina. Fakta ini membuktikan bahwa penjajahan barat juga punya andil besar terhadap genealogi radikalisme.

Ikhwanul-Muslimin Salah satu organisasi masyarakat yang bergerak dalam bidang dakwah islam dimesir dan dunia arab. didirikan oleh Hasan al-Banna, IM di

${ }^{14}$ Najih ar-Ramadhani, Bid'ah Idiologi ISIS, Catatan penistaan ISIS terhadap hadist (Jakarta; Daulat Pres. 2017), hlm. 81 
awal pembentukannya sangat memperhatikan aspek pendidikan islam (TarbiyahIslamiyah), dengan maksud untuk membangun akhlaq yang kuat dan akidah yang benar, sehingga mendorong para jam'ahnya melakukan perbuatan mulia, berangkat dari solidaritas dan keprihatinan mereka terhadap Negara-negara islam, IM kemudian mengirimkan pasukan untuk berjihad di Palestina. pasca pengiriman pasukan tersebut IM yang sebelumnya hanya organisasi kecil mendapat banyak anggota dan makin populer di negara Arab. Namun seiring perjalannya waktu IM semakin tidak terkendali. Banyak tokoh dan anggotanya yang mendirikan beberapa Front Jihad karena berbagai kepentingan dan perbedaan kehendak diantara mereka. Ada yang mendirikan Jama'ah Jihad, Jamaah Takfir Wal-hijrah dan Hizbut-tahrir yang didirikan oleh Taqiyuddin an-Nabhani karena kecewa dengan IkhwanulMuslimin yang dianggapnya terlalu lunak. ${ }^{15}$

Kesamaan latar belakang sejarah dengan Ikhwanul-muslimin inilah yang menjadi sebab munculnya beberapa gerakan radikal Mulai dari Hizbu-tahrir, AlQaeda hingga ISIS. Bahkan Osamah bin laden pendiri al-Qaeda, adalah murid dari Abdullah Azzam yang merupakan dosennya ketika masih kuliah. Abdullah azzam adalah anggota Ikhwanul-muslimin di negaranya saat masih muda. Dari fakta ini bisa disimpulkan bahwa Ikhwanul-Muslimin juga punya andil dan pemicu bagi munculnya banyak aliran dan pergerakan Jihadi.

Hizb-tahrir Secara literal berarti Partai kemerdekaan. pasca runtuhnya Khalifah Turki Usmani HT melihat bahwa umat islam sekarang berada dalam kemunduran. Maka mengembalikan khilafah menjadi target dan agenda utama gerakan ini.

Hizb-tahrir adalah partai politik yang beridiologi islam, bukan organisasi kerohanian, bukan pula lembaga imiiah ataupun akademis, dan jga bukan lembaga social, Hizb-tahrir menganut islam sebagai idiologi dan politik sebagai aktifitasnya. Hizb-tahrir bermaksud membangkitan kembali umat Islam dari kemerosotan yang amat parah, membebaskannya dari ide-ide dan system perundang-undangan Kufur serta membebaskan dari dominasi Negara-negara kafir pada kejayaan masa lampau. ialah dengan cara menegakkan Khilafah-Islamiyah sebagai symbol pemersatu umat islam dan lambang kejayaan kaum muslimin pada masa silam. akan tetapi Hizbtahrir berlebihan dan terlalu bersemangat menyikapi Khilafah, hal ii tergambar dalam statement Syekh Taqiyuddin an-Nabhani sang pendiri Hizb-tahrir: ${ }^{16}$

"Berpangku tangan dari usaha mendirikan seorang khalifah bagi kaum muslimin adalah perbuatan dosa yang paling besar, karena hal tersebut berarti

15 Tim AFKAR Ma'had Aly MHM Lirboyo, Kritik Idiologi Radikal, (Kediri; Lirboyo Pres.2019), hlm 11-12

16 Taqiyuddin An-Nabhani, As-Syahsiyatul-islamiyah, (Beirut; Darul-ummah.1994), jilid III. HIm.19 
berpangku tangan dari melaksanakan kewajiban islam yamg paing penting, dan bahkan wujudnya islam dalam kancah kehidupan tergantung pada adanya khilafah.

Dalam pernyataan diatas an-Nabhani menganggap orang yang tidak ikut memperjungkan visi-misinya Hizb-tahrir tentang khilafah, berdosa besar. Menurutnya pula ketika khilafah tidak ada, maka islam pun tidak ada. Jadi menurut Hizb-tahrir umat islam di muka bumi telah Kafir sejak satu abad yang lalu, setelah system khilafah dihapus dari Negara Turki.

Hizb-tahrir dalam melancarkan gerakannya, tidak secara frontal seperti gerakan yang mengatasnamakan islam lainnya, seperti ISIS, Jabhatun-Nushro, Majlis Mujahidin, Anshor ad-Daulah,/Tauhid, namun secara bertahap. di Indonesia memang belum ada bukti kuat yang menunjukkan keterlibatan organisasi tersebut dalam tindak kekerasan dan terorisme. organisasi ini hanya bersifat radikal dalam gagasan politiknya, namun menekankan cara-cara damai untuk mencapai tujuannya, radikalisme Hizb-tahrir tergambar dari perjuangannya yang menginginkan perubahan system politik melalui penghancuran Negara bangsa (Nation-State) dan menggantinya dengan Negara islam dibawah satu komando Khilafah.

Sementara ISIS, atau ad-Daulah-islamiyah fil-Iraq wasy-Syam (Da'isy) terlahir dari gerakan jihadis Irak Jama'atut-Tauhid wal-Jihad pimpinan Abu Mus'ab az-Zarqawi, organisasi ini bekerjasama dengan al-Qaeda pimpinan Osama bin laden. Setelah bersekutu dengan Al-Qaeda nama Jamaatut-Tauhid wal-Jihad diganti menjadi Tandzim Qae'dat al-Jihad fi Balad al-Rafidlain.(Organisasi jhad al-Qaeda di kawasan dua sungai). yang kemudian lebih dikenal dengan AQI, mulanya Az_Zarqawi hanya menjadi sekutu Al-Qaeda, namun setelah dimulainya perang, ia bergabung total dan menjadi komandan lapangan untuk Osama bin laden.

Pada tahun 2006 az-Zarqawi meregang nyawa di tangan tentara Amerika serikat. Setelah kematian az-Zarqawi AQI berubah menjadi ISI (Islamic state of Iraq) pimpinan Abu bakar al-Baghdadi, dibawah komando al-Baghdadi, ISI yang semula hanya beroprasi di irak, menerjunkan pasukannya ke Suriah melalui perbatasan provinsi Hasaka. Selanjtnya ISI bergabung juga dengan Jabhat alNushro yang dipimpin oleh Abu Muhammad al-Jolani. Kemudian kolaborasi keduanya membentuk sebuah "kesatuan" yang kemudian disebut dengan Islamic State of Iraq and Syiria (ISIS). ${ }^{17}$

Dalam perjalanannya ISIS menerapkan prinsip teror tidak hanya terhadap Non-muslim tapi juga kepada sesama umat islam, sebagai ekstrimis Takfiri Khawarij, obyek yang disasar ISIS adalah siapapun yang menghalangi mereka, dangan faham radikalnya ISIS tak segan-segan melakukan bom Bunuh diri, Pembantaian, Perampokan bank, Penghancuran Masjid, makam dan sebagaianya.

\footnotetext{
${ }^{17}$ Najih ar-Ramadhani, Op Cit, hlm.71
} 
Menurut klaim PBB aksi brutal ISIS ini telah banyak memakan korban hingga ribuan nyawa yang mayoritas adalah warga sipil, serta juga puluhan ribu warga suriah yang harus mengungsi dari negaranya sendiri.

Aksi kekejaman yang dilakukan oleh ISIS sontak membuat dunia bersuara mulai dari kalangan persatuan ulama Muslim Se-dunia, hingga PBB melalui dewan keamananya bahkan seluruh negaradi dunia, mengecam karena ISIS dianggap telah mencederai martabat kemanusiaan dengan cara yang teramat buruk. Semua ini menunjukkan bahwa kehadiran ISIS hanyalah motif politik kekuasaan belaka. Mereka bertopeng dibalik klaim-klaim syari'ah dan khilafah untuk menjustifikasi aksi-aksi teror mereka. ISIS tampak telah mencoreng citra islam dan menampilkan wajah islam dari Rahmatan-lil-alamin menjadi agama yang mengerikan. Jadi Sejarah singkat mulai Khawarij hingga ISIS menunjukkan bahwa seluruh kelompok ini sebenarnya masih menggunakan Slogan yang sama, serta muncul karena faktor yang sama. Meskipun ada perbedaan diantara mereka namun perbedaan itu tidaklah esensial dan subtantif. Karena perbedaan itu muncul akibat perbedaan zaman antara radikalisme khawarij dan kelompok radikalisme modern.Wallahu-a 'lam

\section{PENUTUP}

Berdasarkan ulasan dan paparan tentang Genealogi radikalisme di atas ada beberapa poin yang bisa diambil kesimpulan:

Pertama, Bahwa radikalisme adalah faham, aliran atau gerakan yang mengingikan perubahan baik dalam faham keagamaan atau idiologis, sosial dan politik dengan cara kekerasan dan drastis , radikalisme adalah tindakan menyimpang dan jauh dari nilai-nilai islam bahkan bertolak belakang dengan islam.

Kedua, Radikalisme genealoginyanya sudah ada sejak era klasik bahkan sejak zaman nabi Muhammad SAW, kemudian dilanjutkan aksinya oleh kelompok khawarij mulai zaman Khalifah Ali bin thalib,

Ketiga, di era Kontemporer radikalisme sebetulnya mengambil teladan dari pola gerakan Khawarij Meskipun ada perbedaan namun perbedaan itu tidaklah esensial dan subtantif. Karena perbedaan itu muncul akibat perbedaan zaman antara Khawarij dan kelompok radikalisme modern, Takfir menjadi dasar dan pemicu genealogi radikalisme dalam islam, dimana kelompok khawarij adalah Founding father nya, yang kemudian di adopsi oleh kelompok islam modern seperti SalafiWahhabi, Hizbu-tahrir dan ISIS serta kelompok islam modern lain yang menjadikan khawarij sebagai Uswah dalam gerakannya.

Keempat, penjajahan barat juga memiliki andil besar dalam membentuk pergerakan radikal di era kontemporer. radikalisme muncul sebagai reaksi atas penjajahan barat. Negara-negara barat banyak menjajah Negara islam di timur tengah, hal ini memancing reaksi tokoh-tokoh muslim dberbagai wilayah untuk memberikan bantuan dan perlawanan atas penjajahan tersebut. 
Kelima, radikalisme dengan arti gerakan yang menggunakan kekerasan dalam menyebarkan faham dan gagasannya bertentangan dengan islam sebagai agama damai dan mencintai kedamaian, bahkan bertentangan dengan kata Islam itu sendiri yang memiliki arti keselamatan, namun tidak dipungkiri secara historis baik di era klasik maupun kontemporer, memang terdapat kelompok islam tertentu yang menggunakan cara-cara radikal dan anarkis dalam mencapai tujuan politis dan idiologisnya.

\section{REFERENSI}

Abu Zahrah, Tarikhul-Madzahib-Islaamiyah, penj; Abdurrahman Dahlan dan ahmad Qorib, cet 1(Jakarta; logos, 1996)

Ahmad Warson Munawwir, Kamus Al-MUnawwir, cet.25.(Surabaya; Pustaka progresif, 2002)

Ahmad amin, Fajr-islam, (Beirut; Darul-Kutub-Ilmiyah. 2004)

As-Syahrastani, Al-Milal wan-Nihal, (Beirut; darul-fikr. 2005)

Al-Baghdadi, Al-Farqu bayn al-Firaq, (Beirut; darul-kutub-ilmiyah. Tth)

Anzar Abdullah, Gerakan Radikalisme Dalam Islam Perspektif Historis, (Makassar;

ADDIN, Vol.10, no 1,2016)

Azyumardi Azra, Transformasi Politik Islam, (Jakarta; Prenada Media, 2016)

Badan Nasional Penanggulangan Terorisme (BNPT), "Strategi menghadapi paham radikalisme terorisme-Isis", Artikel

Dendy sugono, Kamus Bahasa Idonesia,(Jakarta; Pusat Bahasa, 2008)

Harun nasution, Teologi Islam, Aliran-Aliran, Sejarah, Analisa dan Perbandingan, cet.5 (Jakarta; UI-Pres.2018)

Louis Ma'luf, Al-Munjid Fillughah Wal-A'lam, cet. 28.(Beirut; Darul-Masyriq, 2000)

Muhammad Isma'il Al-Bukhori, Shohih-Bukhori, (Beirut; darul-kutub-ilmiyah, 1998)

Muttaqin, Imamul. "Konsep Al-Kasb dan Modernisasi Islam." Al-Insyiroh: Jurnal Studi Keislaman 1.1 (2015): 23-43.

Najih ar-Ramadhani, Bid'ah Idiologi ISIS, Catatan penistaan ISIS terhadap hadist (Jakarta; Daulat Pres.2017)

Putra, M. Kholil Baita. "Eksistensi Sistem Pesantren Salafiyah dalam Menghadapi Era Modern." Al-Insyiroh: Jurnal Studi Keislaman 1.1 (2015): 87-104.

Ramdhan, Tri Wahyudi. "DIMENSI MODERASI ISLAM." Al-Insyiroh: Jurnal Studi Keislaman 2.2 (2018): 29-48.

Syekh idahram, sejarah berdarah sekte salafi-wahhabi, (Yogyakarta; Pustaka pesantren, 2011) 
Tim ASWAJA NU CENTER JATIM, Khazanah ASWAJA, (Surabaya; ASWAJA NU CENTER PWNU JATIM, 2016)

Tim AFKAR, Kritik Idiologi Radikal, (Kediri; Lirboyo Pres.2019)

Taqiyuddin an-Nabhani, As-Syahsiyatul-islamiyah, (Beirut; Darul-ummah.1994) 